\title{
Integrated approach for selecting efficient Saccharomyces cerevisiae for industrial lignocellulosic fermentations: Importance of yeast chassis linked to process conditions
}

\author{
Carlos E. Costa ${ }^{a}$, Aloia Romaní ${ }^{a}$, Joana T. Cunha a , Björn Johansson ${ }^{\text {b }}$, Lucília Domingues ${ }^{\mathrm{a}, *}$ \\ ${ }^{a}$ CEB - Centre of Biological Engineering, University of Minho, Campus de Gualtar, Braga 4710-057, Portugal \\ ${ }^{\mathrm{b}}$ CBMA - Center of Molecular and Environmental Biology, University of Minho, Campus de Gualtar, Braga 4710-057, Portugal
}

\section{H I G H L I G H T S}

- Four robust yeast strains were engineered with the same xylose metabolic pathway.

- Selection of recombinant yeast were addressed from an integrated process perspective.

- Recombinant strains attained significant variances in xylose uptake/xylitol formation.

- High ethanol yields $(0.40-0.46 \mathrm{~g} / \mathrm{g})$ were obtained from non-detoxified hydrolysates.

- $70-100 \%$ of xylose was consumed in hydrolysate at $40{ }^{\circ} \mathrm{C}$ for selected strains.

\section{A R T I C L E I N F O}

\section{Article history:}

Received 22 October 2016

Received in revised form 2 December 2016

Accepted 4 December 2016

Available online 11 December 2016

\section{Keywords:}

Industrial Saccharomyces cerevisiae strains Xylose metabolic engineering

Non-detoxified hemicellulosic hydrolysates

Yeast background

\begin{abstract}
A B S T R A C T
In this work, four robust yeast chassis isolated from industrial environments were engineered with the same xylose metabolic pathway. The recombinant strains were physiologically characterized in synthetic xylose and xylose-glucose medium, on non-detoxified hemicellulosic hydrolysates of fast-growing hardwoods (Eucalyptus and Paulownia) and agricultural residues (corn cob and wheat straw) and on Eucalyptus hydrolysate at different temperatures. Results show that the co-consumption of xyloseglucose was dependent on the yeast background. Moreover, heterogeneous results were obtained among different hydrolysates and temperatures for each individual strain pointing to the importance of designing from the very beginning a tailor-made yeast considering the specific raw material and process.
\end{abstract}

(c) 2016 Elsevier Ltd. All rights reserved.

\section{Introduction}

Bioethanol production from lignocellulosic feedstocks has become increasingly important in the last years due to the progressive depletion of fossil fuels reserves and the growing importance of food and animal feed industry sustainability (Aditiya et al., 2016). Industrial lignocellulosic fermentations for bioethanol production involve several stages (pretreatment, saccharification and fermentation) each of which poses significant challenges to attain an economical feasible process (Zaldivar et al., 2001). The complex structure of lignocellulosic biomass needs to be disrupted by a pretreatment in order to obtain fermentable sugars from cellulose and hemicellulose. Xylose, which is one of the main sugars obtained from the hemicellulosic fraction, is not naturally consumed by Saccharomyces cerevisiae (the preferred yeast for ethanol large-scale

\footnotetext{
* Corresponding author.

E-mail address: luciliad@deb.uminho.pt (L. Domingues).
}

processes). Furthermore, compounds such as furfural, hydroxymethylfurfural and acetic acid, released during the pretreatment and hydrolysis steps of lignocellulosic material, are known inhibitors of yeast growth and fermentation (Chandel et al., 2013). Additionally, the desirable implementation of high productivity processes, such as simultaneous saccharification and cofermentation, requires a balance between the optimum temperatures of saccharolytic enzymes and fermentation microbes (Jin et al., 2010). Taking these drawbacks into account, a costefficient exploitation of lignocellulosic biomass for bioethanol production requires the construction of genetically modified yeast capable of co-fermenting glucose and xylose, preferably using robust chassis strains, with intrinsic high resistance to inhibitors and to high temperatures (Li et al., 2016; Moysés et al., 2016).

Industrial environments have been identified as an unexplored bioresource of yeast strains with higher robustness and fermentation performance (Pereira et al., 2014a). On the other hand, the strategy commonly performed for selection of an optimal strain 
consists in exposing several yeasts to the individual/separate effect of stress factors or in testing only one lignocellulosic material (Demeke et al., 2013; Li et al., 2015). Recent work has reported heterogeneous outcomes for tolerance genes overexpression (PRS3 and RPB4, genes identified in Pereira et al. (2011a, 2014b)) in different glucose hydrolysates and/or host strain showing that cell tolerance engineering must be customized to the strain background and hydrolysate used in the process (Cunha et al., 2015).

Furthermore, there are indications that industrial isolates may have different intrinsic capabilities to respond to genetic engineering for pentose metabolism (Li et al., 2015). Most strains have to be subjected to more or less prolonged adaptation or evolutionary engineering in order to show appreciable xylose uptake (Demeke et al., 2013). These recent findings point to the necessity of a tailor-made development of lignocellulosic ethanol-producing yeast where specific process variables are all integrated in the selection process for chassis strain. Instead of adapting the yeast strains for xylose fermentation after xylose-pathway genetic engineering one alternative approach would be to select robust yeast chassis for the multiple stress encountered in hydrolysates and then introduce the genetic modification for xylose consumption in the selected chassis. The constructed strains should then be screened taking into account the limitations involved in $2 \mathrm{G}$ bioethanol processes such as source and nature of hydrolysate, quantity and types of inhibitors, process temperature and sugar co-consumption in a broad range of lignocellulosic hydrolysates. In this way and thinking in an industrial setting, a panel of robust genetically engineered strains could be established to cover common variations in process variables such as raw material to create an industrial process that is more resilient to raw material market fluctuations.

Considering this, in the present study, and taking advantage of the novel metabolic pathway assembly tool (Yeast Pathway Kit; Pereira et al., 2016), four industrial S. cerevisiae strains, previously selected as robust and efficient for glucose 2G bioethanol production (Pereira et al., 2014a), were engineered with the same pathway for xylose consumption. These strains were evaluated in terms of fermentation performance in xylose and cofermentation of both glucose and xylose. Furthermore, for a more dose-to-reality approach, the xylose metabolic backgrounds of those strains were also tested using non-detoxified hydrolysates from hydrothermal treatment of two fast growing hardwoods (Eucalyptus globulus and Paulownia tomentosa) and two agricultural residues (corn cob and wheat straw) at 30 and $40{ }^{\circ} \mathrm{C}$.

\section{Materials and methods}

\subsection{Yeast strains}

Four industrial S. cerevisiae isolates were used as chassis strains in this work: CCUG53310, flocculating strain isolated from a Swedish second generation bioethanol plant (Purwadi et al., 2007; Pereira et al., 2014a); PE-2 and CAT-1, isolated from Brazilian first generation bioethanol plants (Basso et al., 2008; Pereira et al., 2011b); and CA11, isolated from Brazilian "cachaça" fermentation processes (Freitas Schwan et al., 2001; Pereira et al., 2010).

\subsection{Strains construction}

The Yeast Pathway Kit developed by Pereira et al. (2016) was used for construction of the pMEC1049 vector (Romaní et al., 2015), containing the xylose utilization pathway. Briefly, this vector contains the XYL1 (N272D; mutated for higher specificity for NADH (Runquist et al., 2010)) and XYL2 genes from Scheffersomyces stipitis, and the endogenous XKS1 and TAL1 genes, under different $S$. cerevisiae promoters TEF1, TDH3, PGI1 and FBA1, respectively. This vector was introduced in the above mentioned industrial strains, CCUG53310 and CA11, using the lithium acetate method (Gietz and Akio, 1988). Transformants were selected in YPD plates $(10 \mathrm{~g} / \mathrm{L}$ yeast extract, $20 \mathrm{~g} / \mathrm{L}$ peptone, $20 \mathrm{~g} / \mathrm{L}$ glucose and $20 \mathrm{~g} / \mathrm{L}$ agar) containing $300 \mu \mathrm{g} / \mathrm{mL}$ of hygromycin. The resultant xylose metabolizing yeast strains were named CCUG53310-X and CA11$X$. PE-2-X (PE-2 strain with the xylose metabolic pathway described above) and CAT-1-X (CAT-1 strain with the xylose metabolic pathway described above) were equally engineered in a previous work where they were designated as MEC1121 and MEC1122, respectively (Romaní et al., 2015). Additionally, a PE-2 strain with the two copies of the GRE3 gene deleted (to remove the principal native route of xylitol production) and containing the same xylose metabolic pathway (Romaní et al., 2015) was also studied in this work, and was named PE-2-X-dGRE3 (also designated MEC1133 in Romaní et al. (2015)). The recombinant strains were kept on xylose medium to maintain selection for the pMEC1049 vector.

\subsection{Hemicellulosic hydrolysates}

Hemicellulosic hydrolysates used in this work were obtained from processing of four lignocellulosic feedstocks (two fast growing hardwoods: Eucalyptus globulus and Paulownia tomentosa wood and two agricultural residues: corn cob and wheat straw) by hydrothermal treatment followed of acid hydrolysis. Conditions of hydrothermal treatment were selected in based of previous works (Rivas et al., 2002; Pereira et al., 2011a; Romaní et al., 2014; Domínguez et al., 2017) and shown in Table 1. The hardness of hydrothermal treatments can be expressed in terms of "severity" $\left(\mathrm{S}_{0}\right)$, defined as the logarithm of the severity factor $\mathrm{R}_{0}$ (Lavoie et al., 2010). After treatment, solid and liquid phases were separated by filtration. Solid phase was recovered and washed for Solid Yield (SY) determination and analysed for chemical composition following standard methods described by NREL protocols (NREL/ TP-510-42618-42622-4218). Liquid phases were subjected to a second step of acid hydrolysis with $1.5 \%(\mathrm{w} / \mathrm{w}) \mathrm{H}_{2} \mathrm{SO}_{4}$ for $45 \mathrm{~min}$ at $121^{\circ} \mathrm{C}$ in an autoclave. Resulting hydrolysates (containing hemicellulose derived compounds) were neutralized with $\mathrm{CaCO}_{3}$ until pH 5 and sterilized by filtration $(0.2 \mu \mathrm{m})$ to be used as fermentation media. Composition of hydrolysates (sugars, acetic acid and furan compounds) was analysed by HPLC and shown in Table 1.

In order to evaluate the nutritional supplementation, hydrolysates were enriched with commercial nutrients $(20 \mathrm{~g} / \mathrm{L}$ peptone and $10 \mathrm{~g} / \mathrm{L}$ yeast extract) and alternatively with low-cost supplements (cheese whey, $16.52 \mathrm{~g} / \mathrm{L}$; urea, $0.86 \mathrm{~g} / \mathrm{L}$; corn steep liquor, $5.79 \mathrm{~g} / \mathrm{L}$; raw yeast extract, $4.10 \mathrm{~g} / \mathrm{L}$ and $\mathrm{K}_{2} \mathrm{O}_{5} \mathrm{~S}_{2}, 0.3335 \mathrm{~g} / \mathrm{L}$ ) as described by Kelbert et al. (2015).

\subsection{Inoculum}

The yeast strains used for inoculum preparation were preserved on YPX solid medium (20 g/L of xylose, $20 \mathrm{~g} / \mathrm{L}$ of technical agar, $5 \mathrm{~g} /$ $\mathrm{L}$ of yeast extract and $10 \mathrm{~g} / \mathrm{L}$ of peptone) at $4{ }^{\circ} \mathrm{C}$ and transferred regularly to fresh medium. Yeast cells for inoculation were grown in $250 \mathrm{~mL}$ Erlenmeyer flasks with a working volume of $100 \mathrm{~mL}$ media composed by $30 \mathrm{~g} / \mathrm{L}$ of xylose, $20 \mathrm{~g} / \mathrm{L}$ of peptone and $10 \mathrm{~g} /$ $\mathrm{L}$ of yeast extract, with orbital shaking $(200 \mathrm{rpm})$ at $30^{\circ} \mathrm{C}$ for $24 \mathrm{~h}$. Biomass was recovered by centrifugation (10 min, $4000 \mathrm{~g}$, $4{ }^{\circ} \mathrm{C}$ ) and pellets were suspended in $0.9 \%(\mathrm{w} / \mathrm{v})$ sodium chloride solution, in order to achieve a final concentration of $200 \mathrm{mg}$ of fresh yeast $/ \mathrm{mL}$. The concentrated cell suspensions were used to inoculate the fermentation media, with a cellular concentration of $5 \mathrm{mg}$ of fresh yeast $/ \mathrm{mL}$ (corresponding to $1.8 \mathrm{mg}$ of dry yeast/ $\mathrm{mL})$. 
Table 1

Characterization of lignocellulosic biomasses (composition of solid phase and hydrolysate) and operational conditions of hydrothermal pretreatment.

\begin{tabular}{|c|c|c|c|c|}
\hline & Eucalyptus globulus & Paulownia tomentosa & Wheat straw & Corn cob \\
\hline \multicolumn{5}{|c|}{ Raw material composition ( $\mathrm{g}$ of component $/ 100 \mathrm{~g}$ of raw material) } \\
\hline Glucan & 45 & 40 & 37 & 34 \\
\hline Xylan & 16 & 15 & 29 & 29 \\
\hline Arabinan & 1.09 & - & 1.5 & 2.8 \\
\hline Acetyl groups & 3.0 & 3.2 & 2.8 & 2.4 \\
\hline Klason Lignin & 28 & 22 & 27 & 25 \\
\hline $\begin{array}{l}\text { Hydrothermal treatment conditions } \\
\text { Solid Yield }\end{array}$ & $\begin{array}{l}\mathrm{S}_{0}=4.08 ; \mathrm{LSR}=8 \mathrm{~g} / \mathrm{g} \\
71.4\end{array}$ & $\begin{array}{l}\mathrm{S}_{0}=4.19 ; \mathrm{LSR}=8 \mathrm{~g} / \mathrm{g} \\
68.9\end{array}$ & $\begin{array}{l}\mathrm{S}_{0}=3.92 ; \mathrm{LSR}=10 \mathrm{~g} / \mathrm{g} \\
60.2\end{array}$ & $\begin{array}{l}\mathrm{S}_{0}=3.83 ; \mathrm{LSR}=8 \mathrm{~g} / \mathrm{g} \\
64.1\end{array}$ \\
\hline \multicolumn{5}{|c|}{ a) Solid phase composition ( $\mathrm{g}$ of component/100 g of hydrothermally pretreated raw material) } \\
\hline Glucan & 59 & 56 & 63 & 52 \\
\hline Xylan & 2.1 & 2.3 & 7.2 & 13 \\
\hline Acetylgroups & - & - & 1.5 & 2.0 \\
\hline Klason Lignin & 34 & 36 & 27 & 25 \\
\hline \multicolumn{5}{|c|}{ b) Hydrolysate composition from acid hydrolysis of autohydrolysis liquor (g/L) } \\
\hline Glucose & 2 & 2 & 3 & 3 \\
\hline Xylose & 16 & 14 & 16 & 26 \\
\hline Arabinose & - & - & - & 3 \\
\hline Acetic acid & 6.2 & 5.2 & 2.6 & 4 \\
\hline Hydroxymethylfurfural & 0.3 & 0.15 & 0.13 & 0.2 \\
\hline Furfural & 1.6 & 0.85 & 0.35 & 0.4 \\
\hline
\end{tabular}

\subsection{Fermentation assays}

The fermentation experiments were carried out in $100 \mathrm{~mL}$ Erlenmeyer flasks (working volume $30 \mathrm{~mL}$ ), at $30^{\circ} \mathrm{C}$ or $40{ }^{\circ} \mathrm{C}$ in an orbital shaker $(150 \mathrm{rpm})$ under oxygen-limited conditions and pH 5 (experiments listed in Tables 2-4). To achieve what has been defined as oxygen-limited conditions, flasks were closed with cotton stopper, allowing the culture to contact with air while maintaining oxygen limitation. The fermentations were monitored by sample collection for HPLC analysis. Biomass concentration in the media was measured by dry cell weight in the end of fermentation. The experiments of this study were performed in duplicate, allowing standard deviation calculation. Besides the hemicellulosic hydrolysates described in Section 2.2 the yeast strains were also tested in YPX (10 g/L of yeast extract, $20 \mathrm{~g} / \mathrm{L}$ of peptone and $45 \mathrm{~g} /$ $\mathrm{L}$ of xylose) and YPDX (10 g/L of yeast extract, $20 \mathrm{~g} / \mathrm{L}$ of peptone, $20 \mathrm{~g} / \mathrm{L}$ of glucose and $50 \mathrm{~g} / \mathrm{L}$ of xylose) media.

\subsection{Determination of fermentation parameters}

Glucose consumption rate $(\mathrm{g} / \mathrm{L} \cdot \mathrm{h})$ was calculated as the difference between culture glucose concentrations at the beginning of the culture (Gt0) and glucose (GtGf) at time tGf divided by tGf. Where Gt0 is the concentration of glucose at initial time $\left(t_{0}\right)$ and tGf is the first time point when glucose is virtually exhausted (indistinguishable from $0 \mathrm{~g} / \mathrm{L}$ by the analytical methods used and achieved at first $6 \mathrm{~h}$ of fermentation).

Xylose consumption rate $(\mathrm{g} / \mathrm{L} \cdot \mathrm{h})$ was calculated in a similar manner, but divided into two phases before and after glucose exhaustion. Thus, two rates were calculated one in the presence and one in the absence of glucose. Thus, xylose consumption rate in presence of glucose was calculated by ratio between xylose consumed while glucose is present $\left(\mathrm{X}_{\mathrm{t} 0}-\mathrm{X}_{\mathrm{tGf}}\right)$ and time needed for glucose consumption $\left(t_{G f}-t_{0}\right)$. Where $X_{t 0}$ is the concentration of xylose at initial time and $\mathrm{X}_{\mathrm{tGf}}$ is the xylose concentration when the glucose was totally consumed. Xylose consumption rate in absence of glucose was calculated by ratio between xylose consumed $\left(X_{t G f}-X_{t E m a x}\right)$ and the time needed for this consumption $\left(t_{E \max }-t_{\mathrm{tGf}}\right) . X_{\mathrm{tEmax}}$ is the concentration of xylose when ethanol achieved the maximum concentration and $t_{\mathrm{Emax}}$ is the time needed to achieve the maximal concentration of ethanol. In media with xylose as only carbon source, xylose consumption rate was calculated by ratio between xylose consumed when the ethanol achieved the maximum concentration $\left(\mathrm{X}_{\mathrm{t} 0}-\mathrm{X}_{\mathrm{tEmax}}\right)$ and time needed for this xylose consumption $\left(t_{E \max }-t_{0}\right)$.

Ethanol yield $\left(\mathrm{Y}_{\mathrm{P} / \mathrm{S}}\right)$ was calculated by the ratio between maximal ethanol produced in the fermentation that was achieved at $48 \mathrm{~h}$ for synthetic media and within $24-34 \mathrm{~h}$ for hydrolysate media and sugars consumed in this period of time. Biomass yield $\left(Y_{x / s}\right)$ was determined by ratio between dry weight of cells and sugars consumed at the end of fermentation. Fermentation parameters from hydrolysates assays were expressed as ethanol obtained in $\mathrm{g}$ per $100 \mathrm{~g}$ of xylan present in lignocellulosic biomass.

\subsection{Analytical methods}

Samples collected from fermentation runs and from analytical analysis of hydrolysates and pretreated solid fraction were analysed for xylose, glucose, xylitol, acetic acid, ethanol, furfural and HMF concentration by HPLC utilizing a BioRad Aminex HPX-87H column,

Table 2

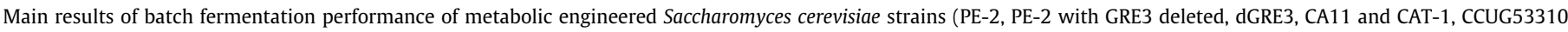
backgrounds with the xylose metabolic pathway, $-\mathrm{X}$ ) in glucose and xylose synthetic media (YPDX is a medium with glucose, xylose, yeast extract and peptone).

\begin{tabular}{|c|c|c|c|c|c|c|c|c|c|}
\hline Run & Yeast & Medium & $\mathrm{Gt}_{0}(\mathrm{~g} / \mathrm{L})$ & $\mathrm{Xt}_{0}(\mathrm{~g} / \mathrm{L})$ & $\mathrm{Gt}_{\mathrm{f}}(\mathrm{g} / \mathrm{L})$ & $\mathrm{Xt}_{\mathrm{f}}(\mathrm{g} / \mathrm{L})$ & $\mathrm{E}_{\max }(\mathrm{g} / \mathrm{L})$ & Xylitol (g/L) & $\mathrm{Y}_{\mathrm{X} / \mathrm{S}}(\mathrm{g} / \mathrm{g})$ \\
\hline 1 & PE-2-X & YPDX & $19.8 \pm 1.3$ & $52.8 \pm 3.5$ & $0.000 \pm 0.000$ & $0.375 \pm 0.109$ & $16.7 \pm 0.0$ & $10.6 \pm 0.6$ & 0.171 \\
\hline 2 & PE-2-X-dGRE3 & YPDX & $20.2 \pm 1.0$ & $51.0 \pm 4.6$ & $0.000 \pm 0.000$ & $0.431 \pm 0.152$ & $19.4 \pm 0.1$ & $7.18 \pm 0.39$ & 0.180 \\
\hline 3 & CA11-X & YPDX & $20.9 \pm 2.9$ & $42.9 \pm 4.0$ & $0.000 \pm 0.000$ & $0.882 \pm 0.181$ & $15.3 \pm 0.7$ & $5.11 \pm 0.24$ & 0.289 \\
\hline 4 & CAT-1-X & YPDX & $18.7 \pm 0.7$ & $42.5 \pm 0.1$ & $0.000 \pm 0.000$ & $0.650 \pm 0.514$ & $15.5 \pm 0.4$ & $3.22 \pm 0.09$ & 0.262 \\
\hline 5 & CCUG53310-X & YPDX & $20.6 \pm 0.1$ & $43.8 \pm 0.2$ & $0.000 \pm 0.000$ & $30.2 \pm 0.9$ & $8.66 \pm 0.22$ & $1.47 \pm 0.21$ & 0.401 \\
\hline
\end{tabular}

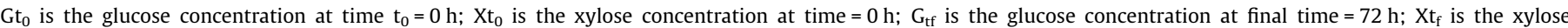

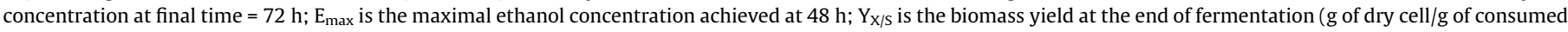
sugar). 
Table 3

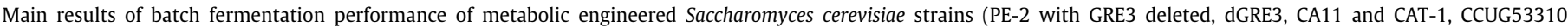
backgrounds with the xylose metabolic pathway, $-\mathrm{X}$ ) in xylose synthetic media (YPX is a medium with xylose, yeast extract and peptone).

\begin{tabular}{|c|c|c|c|c|c|c|c|c|c|}
\hline Run & Yeast & Medium & $\mathrm{Xt}_{0}(\mathrm{~g} / \mathrm{L})$ & $\mathrm{Xt}_{\mathrm{f}}(\mathrm{g} / \mathrm{L})$ & $\mathrm{Y}_{\mathrm{X} / \mathrm{S}}(\mathrm{g} / \mathrm{g})$ & $\mathrm{X}_{\mathrm{CR}}(\mathrm{g} / \mathrm{L} \cdot \mathrm{h})$ & $\mathrm{E}_{\max }(\mathrm{g} / \mathrm{L})$ & Xylitol (g/L) & $\mathrm{Y}_{\mathrm{P} / \mathrm{S}}(\mathrm{g} / \mathrm{g})$ \\
\hline 6 & PE-2-X-dGRE3 & YPX & $48.6 \pm 1.3$ & $0.000 \pm 0.000$ & 0.278 & $0.980 \pm 0.012^{\mathrm{c}}$ & $10.3 \pm 0.2^{\mathrm{d}}$ & $8.08 \pm 0.32^{d}$ & $0.209 \pm 0.012^{b}$ \\
\hline 7 & CA11-X & YPX & $43.3 \pm 1.5$ & $0.375 \pm 0.025$ & 0.341 & $0.781 \pm 0.020^{\mathrm{b}}$ & $7.26 \pm 0.43^{b}$ & $6.73 \pm 0.43^{c}$ & $0.194 \pm 0.002^{b}$ \\
\hline 8 & CAT-1-X & YPX & $41.8 \pm 0.8$ & $0.252 \pm 0.061$ & 0.374 & $0.779 \pm 0.004^{\mathrm{b}}$ & $8.67 \pm 0.10^{c}$ & $3.63 \pm 0.34^{\mathrm{b}}$ & $0.227 \pm 0.004^{b}$ \\
\hline 9 & CCUG53310-X & YPX & $41.3 \pm 0.4$ & $34.5 \pm 1.0$ & 0.101 & $0.0734 \pm 0.0041^{a}$ & $0.613 \pm 0.036^{a}$ & $0.53 \pm 0.07^{\mathrm{a}}$ & $0.091 \pm 0.010^{\mathrm{a}}$ \\
\hline
\end{tabular}

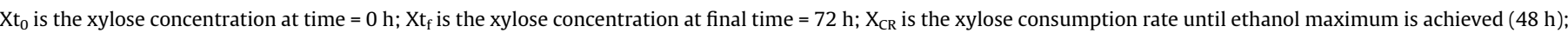

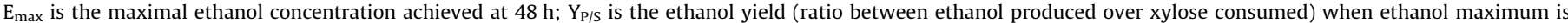

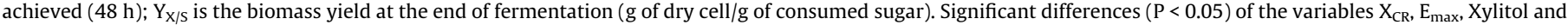
$\mathrm{Y}_{\mathrm{P} / \mathrm{S}}$ are established by a, b, c and d letters.

Table 4

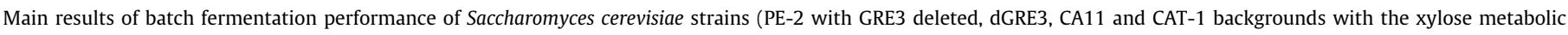
pathway, -X) in lignocellulose hydrolysates (EGW - Eucalyptus globulus; PTW - Paulownia tomentosa wood; WS -wheat straw; CC - corn cob) with low cost supplements.

\begin{tabular}{|c|c|c|c|c|c|c|c|c|c|c|}
\hline Run & Yeast & Hydrolysate & $\begin{array}{l}\mathrm{T} \\
\left({ }^{\circ} \mathrm{C}\right)\end{array}$ & $\mathrm{G}_{\mathrm{t} 0}(\mathrm{~g} / \mathrm{L})$ & $\mathrm{X}_{\mathrm{t} 0}(\mathrm{~g} / \mathrm{L}) *$ & $\mathrm{G}_{\mathrm{tf}}(\mathrm{g} / \mathrm{L})$ & $\mathrm{X}_{\mathrm{tf}}(\mathrm{g} / \mathrm{L})$ & $\mathrm{AA}_{\mathrm{i}}(\mathrm{g} / \mathrm{L})$ & $\begin{array}{l}\mathrm{E}_{\max } / \text { xylan in r.m. (g/100 g } \\
\mathrm{Xn})\end{array}$ & $\begin{array}{l}Y_{E /(G+X y)}(g / \\
g)\end{array}$ \\
\hline 1 & $\begin{array}{l}\text { PE-2-X- } \\
\text { dGRE3 }\end{array}$ & EGW & 30 & $0.994 \pm 0.017$ & $13.2 \pm 0.1$ & $0.000 \pm 0.000$ & $2.10 \pm 0.27$ & $4.30 \pm 0.18$ & $16.7 \pm 0.2$ & 0.430 \\
\hline 2 & CA11-X & EGW & 30 & $1.51 \pm 0.79$ & $15.0 \pm 1.7$ & $0.000 \pm 0.000$ & $0.302 \pm 0.111$ & $3.93 \pm 0.62$ & $12.8 \pm 0.6$ & 0.293 \\
\hline 3 & CAT-1-X & EGW & 30 & $1.27 \pm 0.03$ & $16.5 \pm 0.1$ & $0.000 \pm 0.000$ & $0.000 \pm 0.000$ & $4.28 \pm 0.10$ & $12.0 \pm 0.1$ & 0.278 \\
\hline 4 & $\begin{array}{l}\text { PE-2-X- } \\
\text { dGRE3 }\end{array}$ & PTW & 30 & $1.42 \pm 0.03$ & $13.2 \pm 0.3$ & $0.000 \pm 0.000$ & $1.50 \pm 0.04$ & $5.56 \pm 0.06$ & $15.6 \pm 0.2$ & 0.459 \\
\hline 5 & CA11-X & PTW & 30 & $1.82 \pm 0.42$ & $13.9 \pm 2.3$ & $0.000 \pm 0.000$ & $0.767 \pm 0.417$ & $5.07 \pm 0.71$ & $16.1 \pm 1.0$ & 0.431 \\
\hline 6 & CAT-1-X & PTW & 30 & $2.06 \pm 0.10$ & $14.5 \pm 0.2$ & $0.000 \pm 0.000$ & $0.000 \pm 0.000$ & $6.03 \pm 0.05$ & $13.9 \pm 0.1$ & 0.426 \\
\hline 7 & $\begin{array}{l}\text { PE-2-X- } \\
\text { dGRE3 }\end{array}$ & WS & 30 & $0.958 \pm 0.197$ & $13.2 \pm 0.5$ & $0.000 \pm 0.000$ & $1.14 \pm 0.134$ & $2.74 \pm 0.26$ & $17.6 \pm 1.4$ & 0.400 \\
\hline 8 & CA11-X & WS & 30 & $1.38 \pm 0.28$ & $14.5 \pm 3.2$ & $0.000 \pm 0.000$ & $0.878 \pm 0.154$ & $2.63 \pm 0.33$ & $10.9 \pm 0.1$ & 0.249 \\
\hline 9 & CAT-1-X & WS & 30 & $1.43 \pm 0.09$ & $15.5 \pm 0.1$ & $0.000 \pm 0.000$ & $0.000 \pm 0.000$ & $2.75 \pm 0.07$ & $10.2 \pm 0.6$ & 0.266 \\
\hline 10 & $\begin{array}{l}\text { PE-2-X- } \\
\text { dGRE3 }\end{array}$ & $\mathrm{CC}$ & 30 & $1.12 \pm 0.01$ & $21.5 \pm 0.4$ & $0.000 \pm 0.000$ & $1.44 \pm 0.08$ & $3.82 \pm 0.14$ & $35.6 \pm 0.2$ & 0.424 \\
\hline 11 & CA11-X & $\mathrm{CC}$ & 30 & $1.73 \pm 0.44$ & $24.1 \pm 4.7$ & $0.000 \pm 0.000$ & $1.06 \pm 0.05$ & $3.69 \pm 0.53$ & $23.5 \pm 0.8$ & 0.279 \\
\hline 12 & CAT-1-X & $\mathrm{CC}$ & 30 & $2.16 \pm 0.19$ & $25.7 \pm 1.5$ & $0.000 \pm 0.000$ & $0.119 \pm 0.051$ & $4.43 \pm 0.05$ & $26.4 \pm 0.6$ & 0.306 \\
\hline 13 & $\begin{array}{l}\text { PE-2-X- } \\
\text { dGRE3 }\end{array}$ & EGW & 40 & $0.615 \pm 0.049$ & $14.3 \pm 0.6$ & $0.000 \pm 0.000$ & $6.15 \pm 0.39$ & $4.37 \pm 0.31$ & $14.0 \pm 0.2$ & 0.370 \\
\hline 14 & CA11-X & EGW & 40 & $0.780 \pm 0.028$ & $14.8 \pm 0.0$ & $0.000 \pm 0.000$ & $0.000 \pm 0.000$ & $4.46 \pm 0.26$ & $16.1 \pm 0.1$ & 0.363 \\
\hline
\end{tabular}

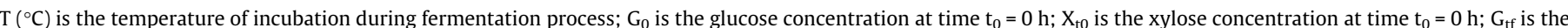

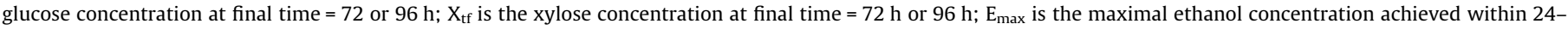
$34 \mathrm{~h} ; \mathrm{Y}_{\mathrm{E} /(\mathrm{G}+\mathrm{X})}$ is ethanol yield from glucose and xylose; $\mathrm{AA}_{\mathrm{i}}$ is the initial concentration of acetic acid in each lignocellulose hydrolysate.

operating at $60{ }^{\circ} \mathrm{C}$, with a mobile phase $0.005 \mathrm{M} \mathrm{H}_{2} \mathrm{SO}_{4}$ and flow rate of $0.6 \mathrm{~mL} / \mathrm{min}$. The peaks corresponding to xylose, glucose, xylitol, ethanol and acetic acid were detected using a Knauer-IR intelligent refractive index detector, whereas furfural and HMF were detected using an Knauer-UV detector set at $210 \mathrm{~nm}$.

\subsection{Statistical analysis}

The software SPSS version 23 (IBM) for Windows was used to perform the statistical analysis. Data are presented as means \pm standard deviation of duplicate determination. Differences among the diverse yeast strains were verified using oneway ANOVA test, with subsequent Tukey's test as a post hoc comparison of means. Statistical significance was established at $P<0.05$ for the comparison, and assembled in homogenous groups represented by letters. Differences between the effect of commercial or low-cost supplementation in the fermentation profiles in hydrolysates were tested by repeated measures two-way ANOVA.

\section{Results and discussion}

3.1. Evaluation of metabolic engineered strains for xylose and glucose fermentation

\subsubsection{Evaluation of yeast strains co-consumption capacity}

In this work, glucose and xylose uptake was evaluated in five different robust yeast strains - PE-2-X, PE-2-X-dGRE3, CA11-X, CAT-1-X and CCUG53310-X -. The different host strains were selected due to high tolerance to inhibitor compounds, superior ability for ethanol performance and high ethanol productivities (Pereira et al., 2014a) and thus used as chassis for xylose metabolic engineering with exactly the same pathway. Fermentation profiles are shown in Fig. 1a (sugar consumption) and b (ethanol and xylitol production). Glucose was rapidly consumed by all strains within $6 \mathrm{~h}$ of fermentation. On the other hand, clear difference in xylose consumption was observed among strains (Fig. 1a). PE-2-X and PE-2-dGRE3 consumed xylose within $48 \mathrm{~h}$ of fermentation and CAT-1-X and CA11-X needed $72 \mathrm{~h}$ for almost complete depletion. CCUG53310-X was able to consume $13.6 \mathrm{~g} / \mathrm{L}$ of xylose, remaining $30.2 \mathrm{~g} / \mathrm{L}$ of xylose in the medium. Differences in the production of ethanol were also observed (Fig. 1b). Maximal ethanol concentration was obtained by PE-2-X-dGRE3. On the other hand, maximal xylitol production was attained by PE-2-X. In order to compare the recombinant strains, Fig. 2 and Table 2 show fermentation parameters and main results obtained from fermentation profiles of these recombinant strains in YPDX medium.

All strains presented a similar glucose consumption rate of about $3 \mathrm{~g} / \mathrm{L} \cdot \mathrm{h}$, except for CCUG53310-X, which showed a consumption rate of $2 \mathrm{~g} / \mathrm{L} \cdot \mathrm{h}$ (Fig. 2a). It has been reported that glucose and xylose are sequentially consumed due to the slower xylose consumption in presence of glucose (Kim et al., 2013). The presence of glucose may suppress xylose consumption, since both sugars enter the cell through the same hexose transporters (Kim et al., 2012). Nevertheless, the presence of glucose in very low concentrations (less than $1 \mathrm{~g} / \mathrm{L}$ ) can facilitate xylose consumption (Lee et al., 2002). 
(a)

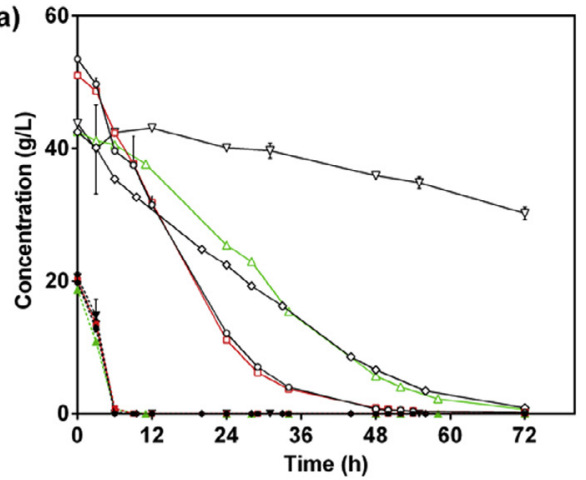

.. Glucose (PE-2-X) $\rightarrow$ Xylose (PE-2-X) -. Glucose (PE-2-X-dGRE3) - Xylose (PE-2-X-dGRE3) - Glucose (CA11-X) $\approx$ Xylose (CA11-X) Glucose (CAT-1-X) Xylose (CAT-1-X) Glucose (CCCUG53310-X) $\rightarrow$ Xylose (CCUG53310-X)

(c)

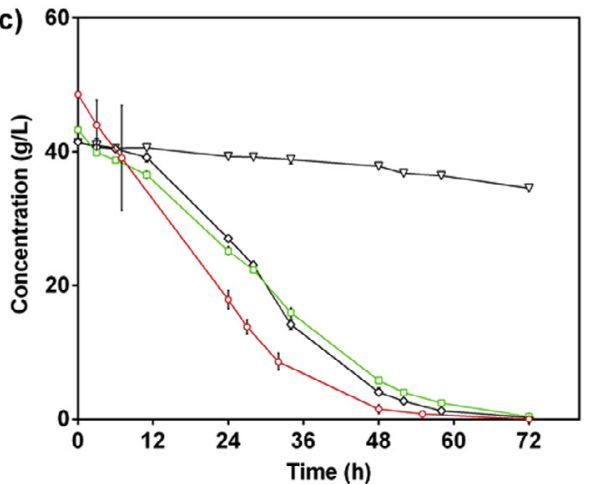

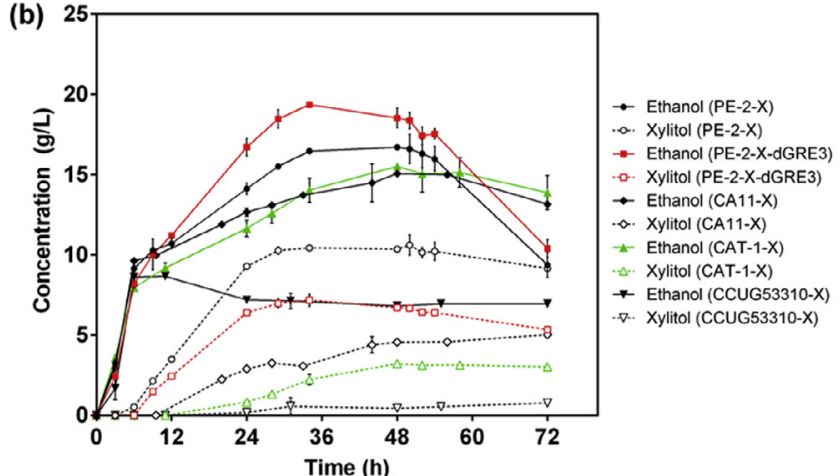

(d)

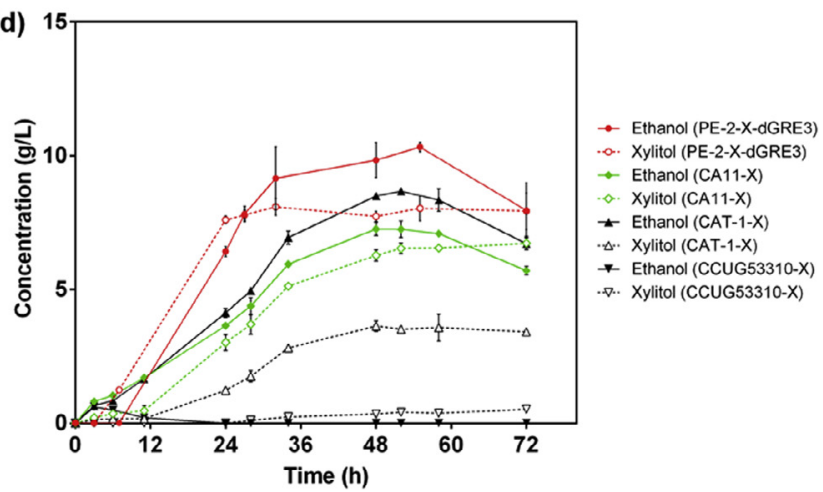

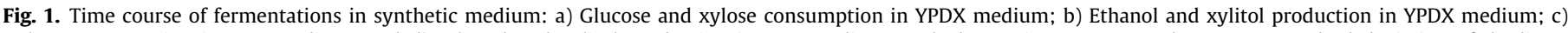

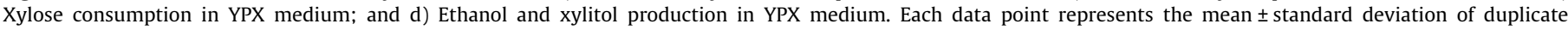
experiments.

In this study, xylose consumption rate was analysed separately, in the presence and absence of glucose (Fig. 2b). When both sugars were present in the medium, PE-2-X showed the greater xylose consumption rate (more than $2 \mathrm{~g} / \mathrm{L} \cdot \mathrm{h}$ ). Nevertheless after glucose depletion, xylose uptake dropped to about half of the initial rate. In comparison, PE-2-X-dGRE3 presented lower xylose consumption rate in the presence of both sugars. Nonetheless, PE-2-XdGRE3 maintained the same xylose consumption rate when on xylose alone (about $1.4 \mathrm{~g} / \mathrm{L} \cdot \mathrm{h}$ ), with no significant differences when compared with PE-2-X without the GRE3 deletion under the same conditions. These consumption rates can be favourably compared to literature, where rates below $0.5 \mathrm{~g} / \mathrm{L} \cdot \mathrm{h}$ were reported in media containing both glucose and xylose in aerobic conditions (Parreiras et al., 2014). CA11-X showed a reduced rate in the first six hours (until glucose depletion), in comparison with PE-2-X and PE-2-XdGRE3, and the consumption rate diminished to half of its initial value after that (Fig. 2b). CAT-1-X seems to present some difficulty in co-fermenting both sugars, being the only strain that had increased consumption rate when xylose was the only carbon source (Fig. 1a). Regardless of this increase, its values were lower than PE-2-X and PE-2-X-dGRE3, which may also suggest some inhibition from glucose on xylose consumption. CUG53310$\mathrm{X}$ showed great deficiency to utilize xylose in both situations (presence or absence of glucose) as can be observed in Fig. 1a.

In terms of ethanol yield, PE-2-X-dGRE3, CAT-1-X and CA11-X appear to be the most efficient strains (Fig. 2c). Regarding xylitol accumulation, CA11-X and CAT-1-X produced low amounts of this by-product (about $5 \mathrm{~g} / \mathrm{L}$ and $3 \mathrm{~g} / \mathrm{L}$, respectively) and CCUG53310 produced less than $2 \mathrm{~g} / \mathrm{L}$, due, most probably, to its slow xylose consumption (Fig. 2d). The deletion of the GRE3 gene in PE-2-XdGRE3 lead to a reduction in xylitol production of more than $30 \%$, when compared to PE-2-X (Fig. 2d), which follows the same tendency shown in previous studies (Träaff et al., 2001;
Träff-Bjerre et al., 2004). Consequently, the ratio between ethanol produced over sugars consumed was significantly higher in fermentation with PE-2-X-dGRE3 $(P<0.05)$, which states clearly the positive influence of the deletion of GRE3 gene on the reduction of the generation of this by-product and improvement of bioethanol yield (Fig. 2d). Nevertheless, xylitol production by PE-2-XdGRE3 remains 1.6 and 2.6-fold higher than the values achieved by CA11-X and CAT-1-X (Fig. 2d), respectively, showing clearly the importance of the yeast chassis on the outcome of metabolic engineering strategies. Despite the fact that GRE3 deletion removes the major native route of production of this by-product (Träaff et al., 2001), xylitol accumulation has been also associated to the activity of an endogenous xylitol dehydrogenase with higher specificity for xylulose (Richard et al., 1999), putative aldose reductases (Garay-Arroyo and Covarrubias, 1999) and a cofactor imbalance in the two-step conversion of xylose into xylulose, resulting in a xylitol pool formation (Eliasson et al., 2001; Almeida et al., 2011).

\subsubsection{Evaluation of yeast strains xylose fermentation capacity}

To evaluate yeast behavior in the presence of xylose as the only carbon source and observe the capacity of modified strains for xylose fermentation, its consumption in synthetic medium was assayed with four of the yeast strains above-mentioned: PE-2-XdGRE3, CA11-X, CAT-1-X and CCUG53310-X. Fermentation profiles are shown in Fig. 1c (xylose consumption) and dethanol and xylitol production). Differences in xylose consumption and ethanol production were also observed with xylose as sole carbon source. Xylose consumption by CA11-X and CAT-1 was only observed after $11 \mathrm{~h}$ of fermentation. Maximal ethanol production was achieved by PE-2-X-dGRE3. Moreover, highest concentration of xylitol (8.08 g/ L) was obtained by this strain. For an easier comparison among strains, Table 3 shows parameters of these fermentation profiles. It is possible to observe that PE-2-X-dGRE3 showed a higher xylose 
(a)

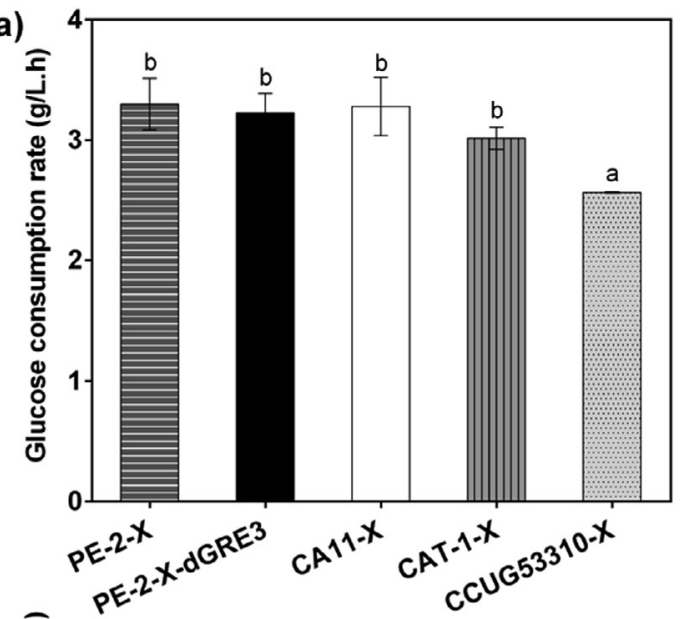

(c)

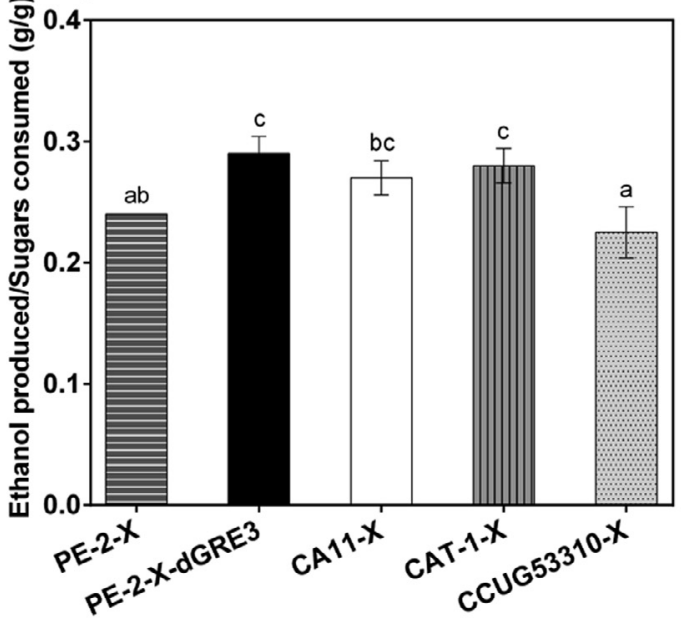

(b)

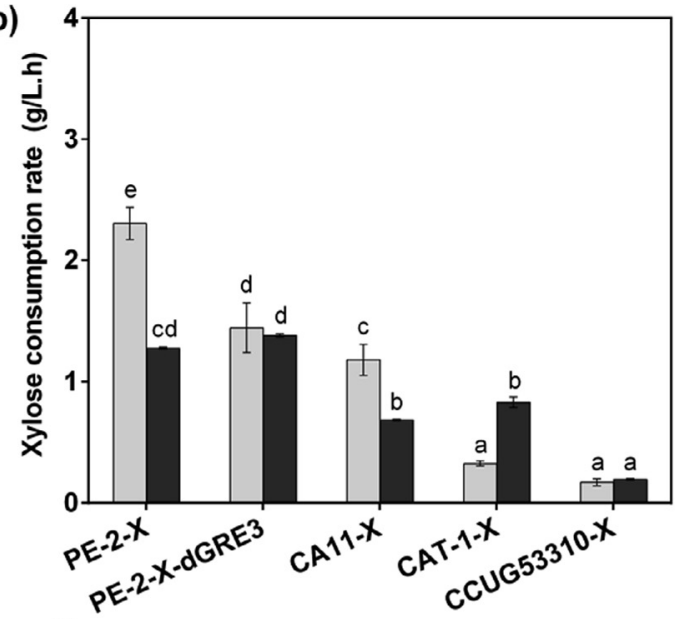

(d)

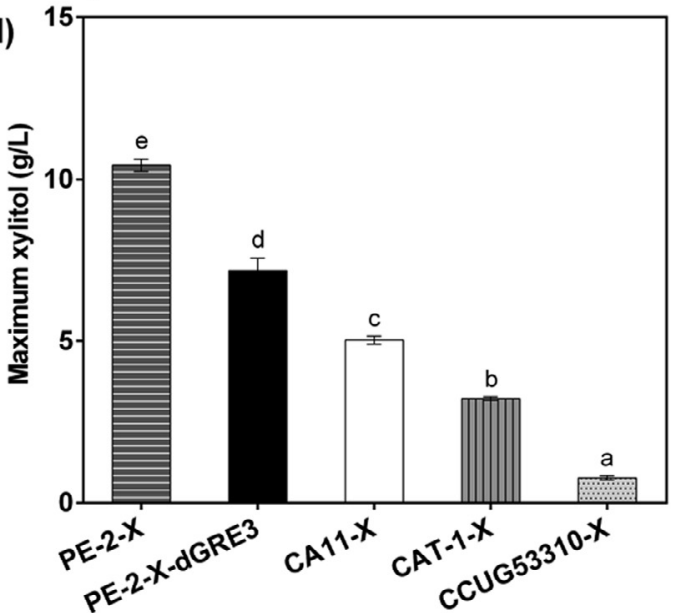

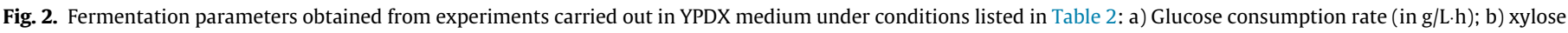

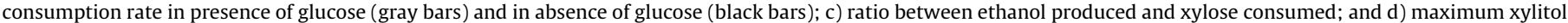
produced.

consumption rate when compared with the other strains tested, consuming about $1 \mathrm{~g} / \mathrm{L}$ of xylose per hour (Table 3 ). In contrast, CCUG53310-X was clearly the less efficient strain, consuming less than $20 \%$ of the xylose present in the medium (Table 3, Run 9), and at a much slower xylose consumption rate. The high consumption rate of xylose was shown by PE-2-X-dGRE3. CA11-X and CAT-1-X, while presenting similar xylose consumption rates, had statistically significant differences $(P<0.05)$ when comparing xylitol production $(6.73 \mathrm{~g} / \mathrm{L}$ and $3.63 \mathrm{~g} / \mathrm{L}$, respectively). Xylitol production by CCUG53310-X was low as a consequence of its low xylose consumption (Table 3). The low ratio between ethanol produced and xylose consumed confirmed the poor efficiency of CCUG53310-X for ethanol production from xylose exclusively, while the other three strains tested in this assay have shown no statistically significant differences between them, achieving ethanol yields of approximately $0.2 \mathrm{~g} / \mathrm{g}$ (Table 3 ). Aerobic xylose consumption has been studied previously (Anderlund et al., 2001; Toivari et al., 2001; Pitkänen et al., 2005) and ethanol yield is usually less than $0.1 \mathrm{~g} / \mathrm{g}$ and accompanied by relatively high xylitol yield (up to $0.62 \mathrm{~g} / \mathrm{g}$ ). In anaerobic conditions ethanol yields of $0.43 \mathrm{~g} / \mathrm{g}$ with low xylitol production have been reported (Karhumaa et al., 2007). Differences on xylitol production, xylose consumption and ethanol concentration among recombinant $S$. cerevisiae strains isolated from different industrial processes (brewery, bakery and food industry) were also reported by Matsushika et al. (2009) in which a flocculating strain from brewery was the most efficient strain for xylose-to-ethanol production in all conditions evaluated. In the present work, the background of strains isolated from similar fermentation environments, bioethanol and "cachaça" industries, were evaluated and proved to differently influence the fermentation outcome, mainly regarding xylitol production and xylose consumption rate.

\subsection{Evaluation of yeast strain performance on lignocellulosic hydrolysates}

\subsubsection{Low-cost supplementation in lignocellulosic hydrolysates fermentation}

Once the yeast strains behavior in synthetic media has been analysed, it is vital to evaluate its performance in real lignocellulosic hydrolysates, where the source of raw material could play an important role. Lignocellulosic hydrolysates present poor nutritional content, creating the necessity of external nutrient supplementation in order to improve ethanol yields (Jørgensen, 2009). Supplementation of E. globulus hydrolysate with low cost agroindustrial by-products has been reported to improve the glucose fermentation rate and ethanol yield using the wild-type PE-2 strain (Kelbert et al., 2015). Here, the PE-2-X-dGRE3 strain was selected to evaluate the effect of substitution of laboratory grade nutrients by low-cost supplements on xylose fermentation performance in all of the hydrolysates used in this work. Results in Fig. 3 show that xylose consumption using both types of supplementation was efficient and similar in all hydrolysates. Additionally, the different supplementation had no effect on the ethanol production on three 
of the hydrolysates (Fig. 3a, b and c), and was slightly superior $(P<0.05)$ with low-cost supplementation in the corn cob hydrolysate (Fig. 3d). Thus, commercial supplementation could be substituted by low-cost supplements in lignocellulosic fermentation processes reducing operational costs. Taking into account these results, subsequent fermentation experiments were carried out with low-cost supplements.

\subsubsection{Xylose consumption of metabolic engineered strains on lignocellulosic hydrolysates}

A commonly used strategy for the evaluation of metabolic or evolutionary engineered strains for xylose consumption is based on screening in a synthetic medium for single inhibitor/stress tolerance (Li et al., 2015) or in only one lignocellulosic hydrolysate and evolutionary engineering to improve tolerance (Demeke et al., 2013; Li et al., 2015). It should be taken into account that the composition of hydrolysates can be heterogeneous since this depends on the pretreatment employed, the conditions of pretreatment and the source of lignocellulosic biomass (Koppram et al., 2014).

In the present study, four hydrolysates from fast growing hardwood and agricultural residue biomasses were employed as fermentation media to evaluate the metabolic engineering yeast performances (time courses shown in Figs. 3 and 4). Due to the low capacity of the strain CCUG53310 for xylose fermentation it was excluded from further studies. Three yeast strains were selected (PE-2-X-dGRE3, CA11-X and CAT-1-X) for fermentation in the four hydrolysates with low-cost supplementation (runs listed in Table 4). As observed, recombinant strains were able to ferment the non-detoxified hydrolysates evaluated in this work (Figs. 3 and 4). In Fig. 5, differences among strains across several hydrolysates can be compared, showing a broad range of conditions. In E. globulus wood, xylose consumption rate was very similar for the three yeast strains (all above $0.3 \mathrm{~g} / \mathrm{L} \cdot \mathrm{h}$ ), but when considering the ratio between ethanol produced to xylose consumed, PE-2-X-dGRE3 performed significantly better (Fig. 5a), with a yield of $0.43 \mathrm{~g} / \mathrm{g}$ in the first $24 \mathrm{~h}$, close to the theoretical yield, while the two other strains exhibited ratios of about $0.30 \mathrm{~g} / \mathrm{g}$ (Table 4, Run 1-3). In P. tomentosa wood hydrolysate, none of the yeast stood out, with all of them showing high ratios of ethanol production over xylose consumption in the first $24 \mathrm{~h}(0.43-0.46 \mathrm{~g}$ of ethanol/g of sugar) (Fig. 5b). The lowest xylose consumption rate in this hydrolysate was influenced by more inhibitor loading (Table 1). These results show great capability of fermentation by the tested strains even with relatively high concentrations of acetic acid present in this hydrolysate (between 5 and $6 \mathrm{~g} / \mathrm{L}$ ).

In wheat straw hydrolysate, xylose consumption rates were essentially similar for the evaluated strains (Fig. 5c), showing significant differences in ethanol yield (PE-2-X-dGRE3 achieved the highest yield of $0.4 \mathrm{~g} / \mathrm{g}$ ). Finally, in corn cob hydrolysates, CA11-X presented a xylose consumption rate of $0.47 \mathrm{~g} / \mathrm{L} \cdot \mathrm{h}$, significantly higher than PE-2-X-dGRE3 (0.41 g/L·h), with CAT-1-X consuming
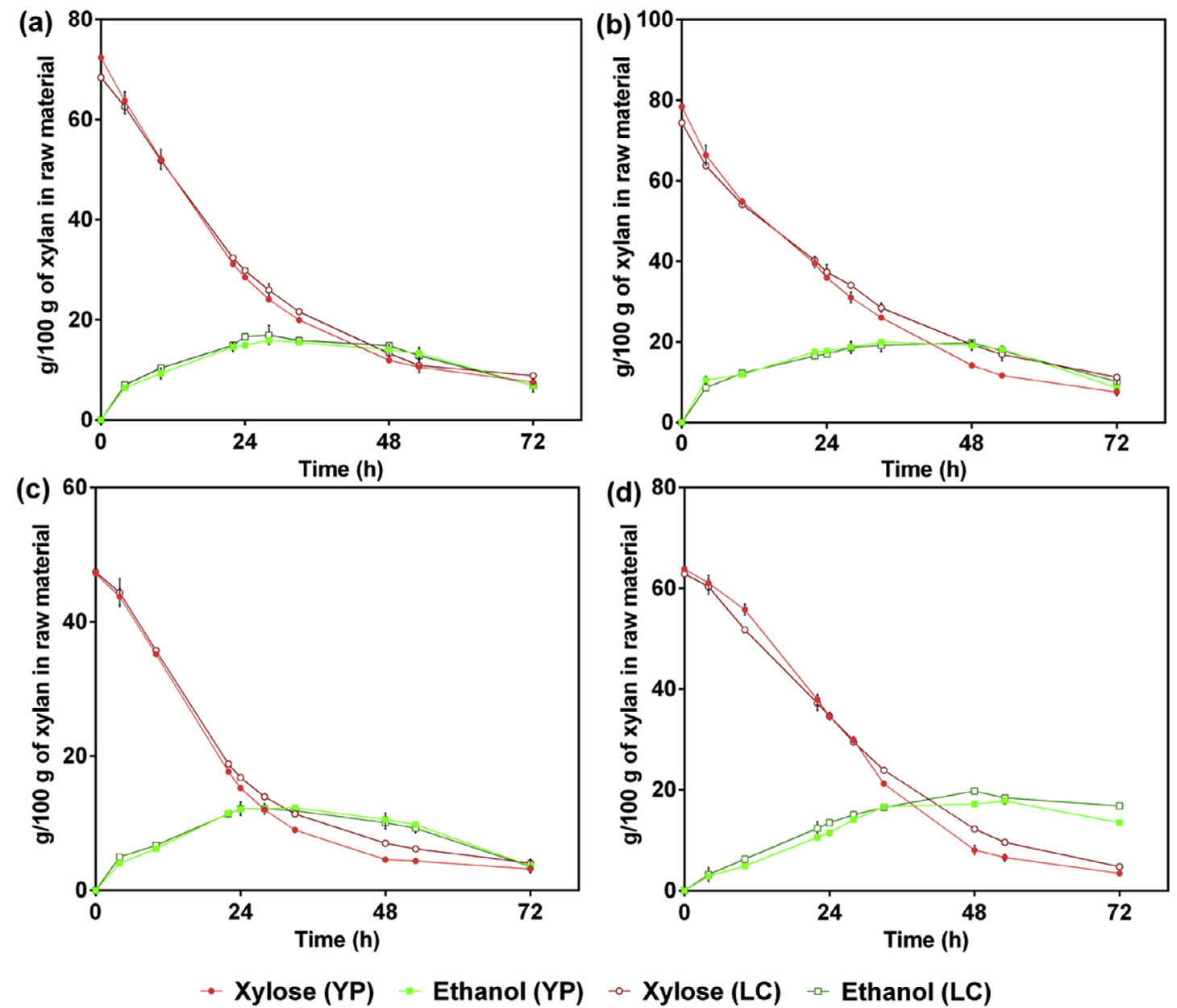

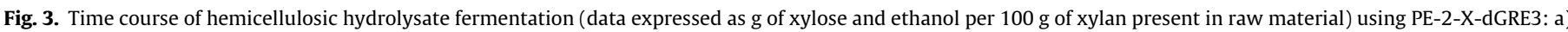

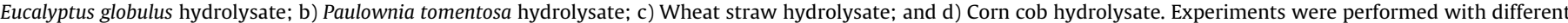

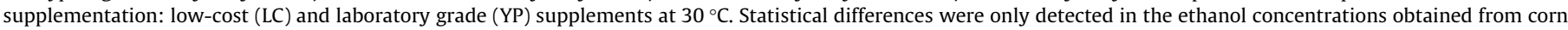
cob hydrolysate $(P<0.05)$. Each data point represents the mean \pm standard deviation of duplicate experiments. 
(a)

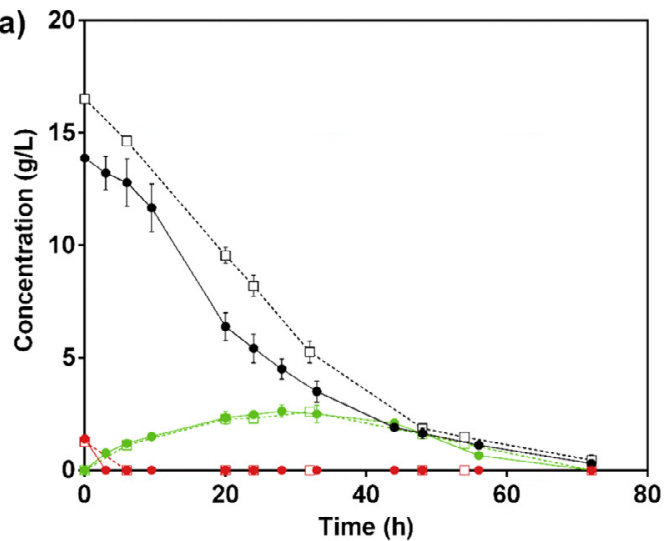

(c)

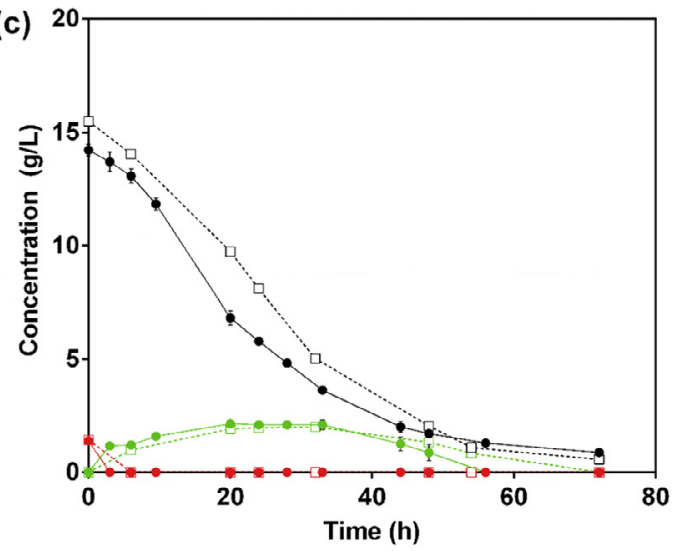

(b)

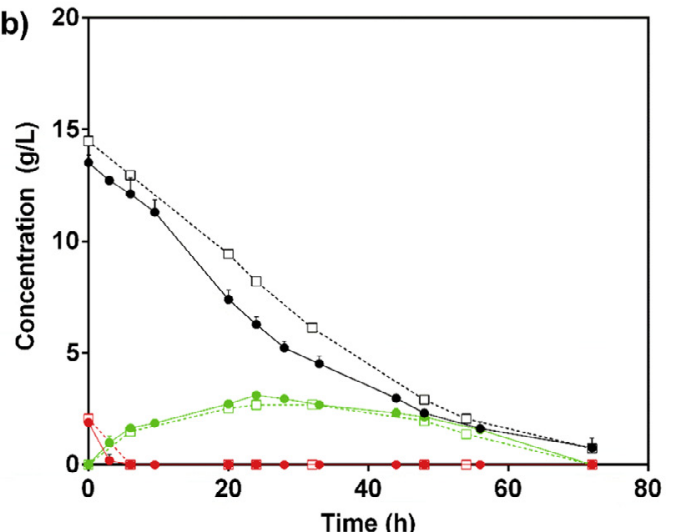

(d)

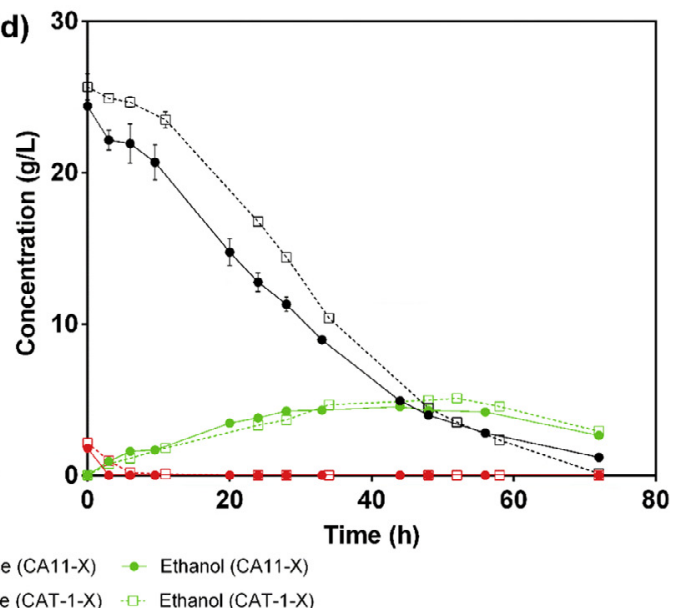

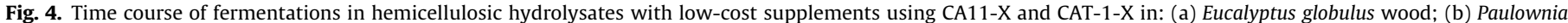
tomentosa wood; (c) Wheat straw; and (d) Corn cob. Each data point represents the mean \pm standard deviation of duplicate experiments.

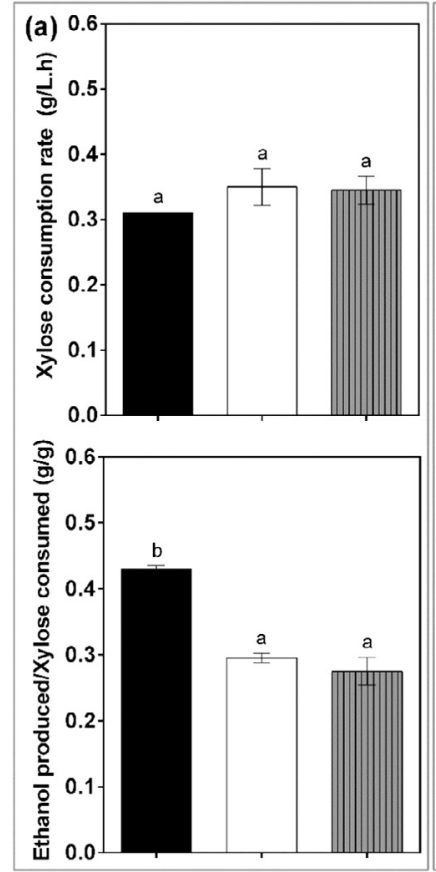

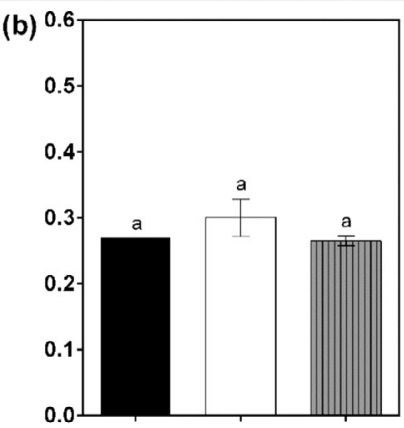

(c)

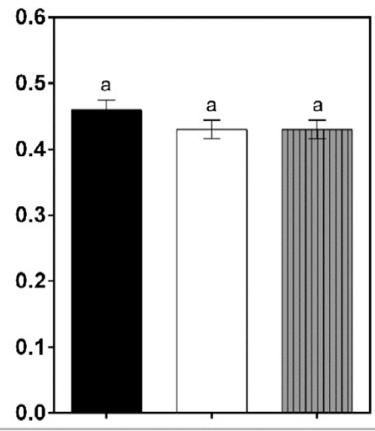

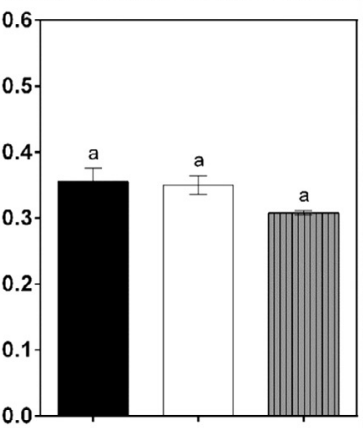

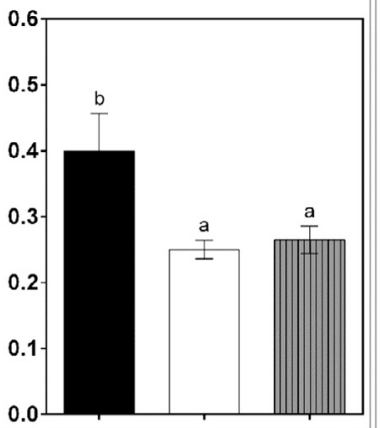

(d)

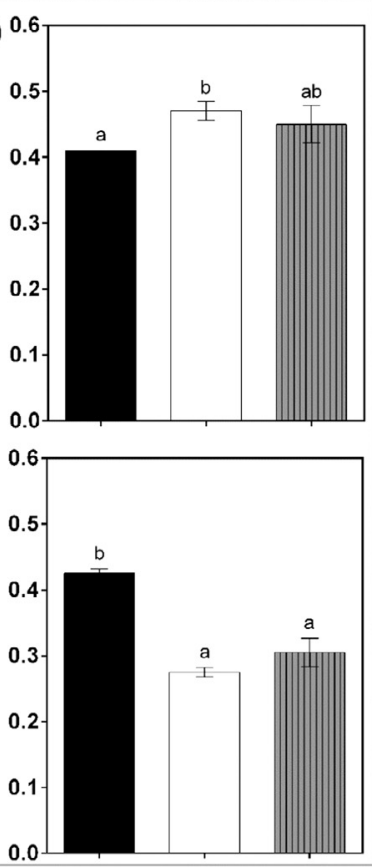

PE-2-X-dGRE3

$\square$ CA11-X III CAT-1-X

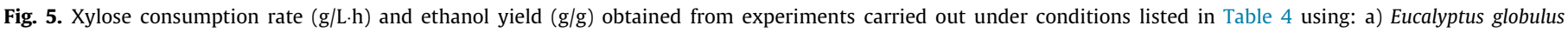
hydrolysate; b) Paulownia tomentosa hydrolysate; c) Wheat straw hydrolysate; and d) Corn cob hydrolysate. 
xylose at a $0.45 \mathrm{~g} / \mathrm{L} \cdot \mathrm{h}$ rate (Table 4, Run 10-12). However, despite lower rate consumption, ethanol yield of PE-2-X-dGRE3 was higher than CA11-X and CAT-1, presenting a ratio of $0.43 \mathrm{~g}$ of ethanol per $\mathrm{g}$ of xylose consumed (Fig. 5d).

Overall, lower xylose consumption was obtained in hydrolysates of fast growing hardwoods (Paulownia and Eucalyptus) when compared to hydrolysates from agricultural residues, corn cob and wheat straw (Figs. 3 and 4). This fact could be due to higher acetic acid concentration in hardwood hydrolysates (Table 4). Acetic acid is one of the most inhibitory compounds released from hemicellulose during pretreatment, affecting greatly both growth and ethanol fermentation of yeast strains (Demeke et al., 2013). Its effects are known to be more severe for xylose fermentation than for glucose fermentation (Casey et al., 2010) and the presence of acetic acid in concentrations of about $4-5 \mathrm{~g} / \mathrm{L}$ is capable of decreasing xylose consumption (Casey et al., 2010; Demeke et al., 2013). The overall relatively low xylose consumption rates obtained in these hydrolysates comparing with synthetic media (S1 in Supplementary data) may be due to synergistic toxic effects of acetic acid, phenolics, furfural and hydroxymethylfurfural present in the hydrolysates composition (Ko et al., 2016).

Direct comparison with results obtained in the literature is not straightforward due to process complexity and heterogeneity that includes: type of pretreatment (hydrothermal or acid), the source of raw material that determines the operational conditions and consequently the inhibitor compounds released, the background of selected strain and the metabolic pathway used. Nevertheless some comparable examples can be picked up from literature where interesting ethanol yields were reported for recombinant strains in specific hydrolysates. Koppram et al. (2013) reported efficient ethanol production with a recombinant KE6-12 strain carrying the XR-XDH pathway in simultaneous saccharification and cofermentation fed-batch assays in corn cob hydrolysate, with ethanol yields up to $0.39 \mathrm{~g} / \mathrm{g}$. Ko et al. (2016) reported for the SXA-R2 PE strain, expressing the XI pathway, in oak hardwood hydrolysate with approximately $6 \mathrm{~g} / \mathrm{L}$ of acetic acid, an ethanol yield of $0.43 \mathrm{~g} / \mathrm{g}$. Studies using wheat straw as feedstock with industrial recombinant yeast strains expressing also the XR-XDH pathway have reported ethanol yields from $0.39 \mathrm{~g} / \mathrm{g}$ (KE6-12 strain) up to $0.48 \mathrm{~g} / \mathrm{g}$, with TMB3400 (Erdei et al., 2012, 2013). While these results were obtained in fed-batch fermentation, the ethanol yields obtained in this work stand among those. Besides in this study, the hydrolysates were supplemented with low cost nutrients and not with expensive laboratory grade yeast extract and/or peptone. Still worth of note are the results obtained in this work that show differences between the engineered strains evaluated depending on the lignocellulosic hydrolysate used, supporting the idea that the selection of yeast for integrated lignocellulosic bioethanol processes should be addressed from a global perspective (considering all hurdles at once). The selection of the yeast chassis cell and advanced engineering strategies should take into account from the very beginning the process conditions and biomass material that will be used in order to attain a high-productivity process.

\subsubsection{Thermotolerance evaluation in hemicellulosic hydrolysate fermentations}

Thermotolerance is another potentially attractive feature to be evaluated since high temperatures are necessary for the enzymatic saccharification of pretreated lignocellulosic biomass. From the results shown above, it is possible to observe that PE-2-X-dGRE3 is the yeast strain with consistently higher ethanol yields in both synthetic and hydrolysate media. On the other hand, CA11-X has been shown to exhibit efficient glucose fermentation at temperatures higher than $30{ }^{\circ} \mathrm{C}$ (Ruiz et al., 2012). For these reasons, both strains were compared for their ability to ferment E. globulus hydrolysate at $40^{\circ} \mathrm{C}$. Fig. 6 shows the fermentation profiles obtained by these strains. At this temperature, it was possible to observe that CA11-X was able to consume all xylose present in the medium (Table 4, Run 14) at a higher consumption rate $(0.36 \mathrm{~g} / \mathrm{L} \cdot \mathrm{h} \pm 0.02)$, while PE-2-X-dGRE3 (Table 4, Run 13) consumed approximately $70 \%$ of xylose, at a consumption rate of $0.24 \mathrm{~g} / \mathrm{L} \cdot \mathrm{h} \pm 0.02$. Probably, a synergetic effect occurs between temperature and hydrolysate inhibition when temperature is increased from 30 to $40{ }^{\circ} \mathrm{C}$ (Kelbert et al., 2016). Ethanol yield was also higher in CA-11-X fermentation, with production of almost $16 \mathrm{~g}$ of ethanol per $100 \mathrm{~g}$ of xylan in raw material, against less than $14 \mathrm{~g}$ of ethanol in the same condition (Table 4). Also, when comparing these results with the same fermentations at $30^{\circ} \mathrm{C}$, it is possible to observe that PE-2-X-dGRE3 presents a significant reduction in xylose consumption rate, while CA11-X maintains a constant value. The efficient performance of CA11-X strain at $40{ }^{\circ} \mathrm{C}$ would be an interesting starting point to advance towards integrated process by a simultaneous saccharification and fermentation comprising solid cellulosic fraction in which enzymes are required together with xylose rich hydrolysate.

\subsection{Overall comparison of industrial S. cerevisiae backgrounds}

The strategy followed in this work allows the identification of potential chassis strains with suitable backgrounds to cope with process-specific challenges that arise during lignocellulosic bioethanol production. An initial screening for evaluation of cofermentation of glucose and xylose showed differences between the strains inherent capacities for xylose consumption: while PE2-X, PE-2-X-dGRE3 and CA11-X were capable of simultaneously consume glucose and xylose, CAT-1-X showed difficulties in coconsuming both sugars. Additionally, the CCUG53310-X strain, that has been described to efficiently produce ethanol from glucose in the presence of lignocellulosic-derived inhibitors (Pereira et al., 2014a), has been shown here to be incapable of metabolizing xylose, making it unfeasible as chassis choice for valorization of lignocellulosic hydrolysates with high contents of this sugar. When comparing all strains for their capacity to metabolize xylose in synthetic media, both in the presence and absence of glucose, we observed a superior performance by PE-2-X and PE-2-X-dGRE3. Nonetheless, the PE- 2 strain presented an innate propensity for xylitol accumulation, and such strains may benefit from an alterna-

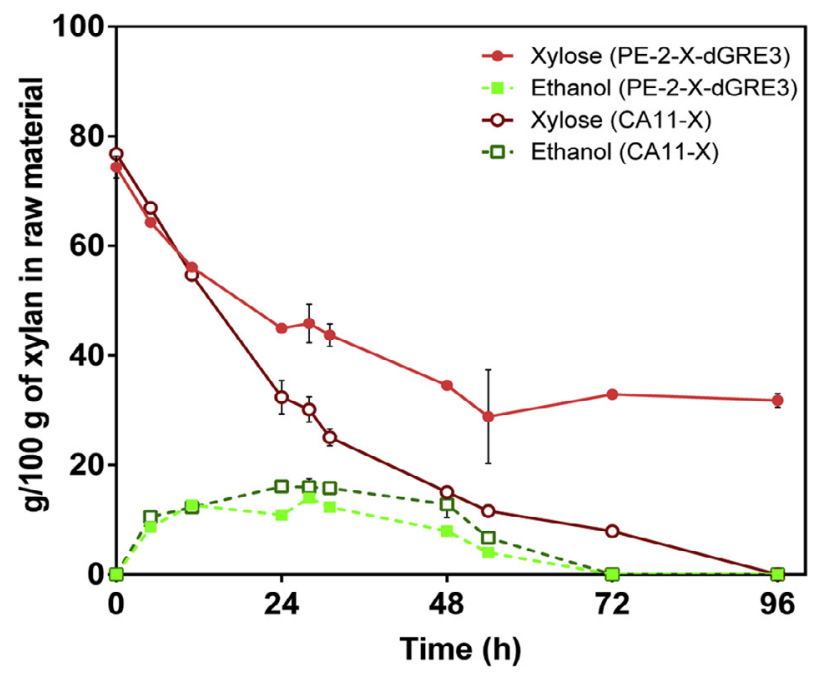

Fig. 6. Time course fermentation profiles of Eucalyptus globulus hydrolysates with low-cost supplements at $40^{\circ} \mathrm{C}$ using PE-2-X-dGRE3 (filled circles) and CA11-X (empty circles). Each data point represents the mean \pm standard deviation of duplicate experiments. 
tive xylose metabolic pathway, such as the non-cofactor-requiring xylose isomerase pathway. This highlights the importance of adjusting the metabolic engineering strategy to the genetic background of the chassis strains.

In a subsequent evaluation of strains fermentation performance in real lignocellulosic hydrolysates, it was observed that the presence of inhibitory compounds clearly hampered xylose consumption rate comparing with synthetic media (see S1 in Supplementary data), supporting the importance of testing several challenging conditions simultaneously. Moreover, the necessity of adjusting the strain selection to the specific inhibitory load of different hydrolysates was underlined by the heterogeneous results obtained from the four hydrolysates tested: all strains had similar performances in the Paulownia hydrolysate, while PE-2-X-dGRE3 achieved superior ethanol yields in the other three hydrolysates.

Despite the distinguished overall results of PE-2-X-dGRE3, the CA11-X strain had a superior and remarkable performance in fermentation of $E$. globulus hydrolysate at $40^{\circ} \mathrm{C}$, a clear consequence of its thermotolerant background. This result highlights, not only the importance of the strain background, but also the necessity of performing screenings with integration of all the major obstacles for efficient bioethanol production from lignocellulosic material: xylose consumption, inhibitory loads and higher process temperatures.

\section{Conclusions}

In this work, four S. cerevisiae strains were engineered with the same metabolic pathway in order to identify a suitable chassis to be used in lignocellulosic fermentation process. Recombinant strains showed significant differences in xylose consumption and xylitol formation, with PE-2-X-dGRE3 and CA11-X exhibiting the most promising performances. In non-detoxified hydrolysates at $30{ }^{\circ} \mathrm{C}, 0.40-0.46 \mathrm{~g} / \mathrm{g}$ of ethanol yields were obtained. At $40^{\circ} \mathrm{C}, 70$ and $100 \%$ of xylose were consumed by PE-2-X-dGRE3 and CA11$\mathrm{X}$, respectively. The heterogeneous outcomes observed for different strains highlight the importance of carefully addressing the engineering of yeast strains for efficient lignocellulosic-to-ethanol production processes.

\section{Acknowledgements}

The authors acknowledge the financial support from the Strategic Project of UID/BIO/04469/2013 CEB Unit and BioTecNorte operation (NORTE-01-0145-FEDER-000004) funded by the European Regional Development Fund under the scope of Norte2020 - Programa Operacional Regional do Norte.

\section{Appendix A. Supplementary data}

Supplementary data associated with this article can be found, in the online version, at http://dx.doi.org/10.1016/j.biortech.2016.12. 016.

\section{References}

Aditiya, H.B., Chong, W.T., Mahlia, T.M.I., Sebayang, A.H., Berawi, M.A., Nur, H., 2016 Second generation bioethanol potential from selected Malaysia's biodiversity biomasses: a review. Waste Manag. 47, 46-61.

Almeida, J.R.M., Runquist, D., Sànchez Nogué, V., Lidén, G., Gorwa-Grauslund, M.F., 2011. Stress-related challenges in pentose fermentation to ethanol by the yeast Saccharomyces cerevisiae. Biotechnol. J. 6, 286-299.

Anderlund, M., Rådström, P., Hahn-Hägerdal, B., 2001. Expression of bifunctional enzymes with xylose reductase and xylitol dehydrogenase activity in Saccharomyces cerevisiae alters product formation during xylose fermentation. Metab. Eng. 3, 226-235.

Basso, L.C., De Amorim, H.V., De Oliveira, A.J., Lopes, M.L., 2008. Yeast selection for fuel ethanol production in Brazil. FEMS Yeast Res. 8, 1155-1163.
Casey, E., Sedlak, M., Ho, N.W.Y., Mosier, N.S., 2010. Effect of acetic acid and pH on the cofermentation of glucose and xylose to ethanol by a genetically engineered strain of Saccharomyces cerevisiae. FEMS Yeast Res. 10, 385-393.

Chandel, A.K., da Silva, S.S., Singh, O.V., 2013. Detoxification of lignocellulose hydrolysates: Biochemical and metabolic engineering toward white biotechnology. BioEnergy Res. 6, 388-401.

Cunha, J.T., Aguiar, T.Q., Romaní, A., Oliveira, C., Domingues, L., 2015. Contribution of PRS3, RPB4 and ZWF1 to the resistance of industrial Saccharomyces cerevisiae CCUG53310 and PE-2 strains to lignocellulosic hydrolysate-derived inhibitors. Bioresour. Technol. 191, 7-16.

Demeke, M.M., Dietz, H., Li, Y., Foulquié-Moreno, M.R., Mutturi, S., Deprez, S., Den Abt, T., Bonini, B.M., Liden, G., Dumortier, F., Verplaetse, A., Boles, E., Thevelein, J. M., 2013. Development of a D-xylose fermenting and inhibitor tolerant industrial Saccharomyces cerevisiae strain with high performance in lignocellulose hydrolysates using metabolic and evolutionary engineering. Biotechnol. Biofuels 6, 89.

Domínguez, E., Romaní, A., Domingues, L., Garrote, G., 2017. Evaluation of strategies for second generation bioethanol production from fast growing biomass Paulownia within a biorefinery scheme. Appl. Energy 187, 777-789.

Eliasson, A., Hofmeyr, J.-H.S., Pedler, S., Hahn-Hägerdal, B., 2001. The xylose reductase/xylitol dehydrogenase/xylulokinase ratio affects product formation in recombinant xylose-utilising Saccharomyces cerevisiae. Enzyme Microb. Technol. 29, 288-297.

Erdei, B., Frankó, B., Galbe, M., Zacchi, G., 2012. Separate hydrolysis and cofermentation for improved xylose utilization in integrated ethanol production from wheat meal and wheat straw. Biotechnol. Biofuels 5, 1-12.

Erdei, B., Hancz, D., Galbe, M., Zacchi, G., 2013. SSF of steam-pretreated wheat straw with the addition of saccharified or fermented wheat meal in integrated bioethanol production. Biotechnol. Biofuels 6, 169.

Freitas Schwan, R., Mendonça, A.T., Da Silva, J.J., Rodrigues, V., Wheals, A.E., 2001. Microbiology and physiology of Cachaça (Aguardente) fermentations. Antonie van Leeuwenhoek. Int. J. Gen. Mol. Microbiol. 79, 89-96.

Garay-Arroyo, A., Covarrubias, A.A., 1999. Three genes whose expression is induced by stress in Saccharomyces cerevisiae. Yeast 15, 879-892.

Gietz, R.D., Akio, S., 1988. New yeast-Escherichia coli shuttle vectors constructed with in vitro mutagenized yeast genes lacking six-base pair restriction sites. Gene 74, 527-534.

Jin, M., Lau, M.W., Balan, V., Dale, B.E., 2010. Two-step SSCF to convert AFEX-treated switchgrass to ethanol using commercial enzymes and Saccharomyces cerevisiae 424A(LNH-ST). Bioresour. Technol. 101, 8171-8178.

Jørgensen, H., 2009. Effect of nutrients on fermentation of pretreated wheat straw at very high dry matter content by Saccharomyces cerevisiae. Appl. Biochem. Biotechnol. 153, 44-57.

Karhumaa, K., Garcia Sanchez, R., Hahn-Hägerdal, B., Gorwa-Grauslund, M.-F., 2007. Comparison of the xylose reductase-xylitol dehydrogenase and the xylose isomerase pathways for xylose fermentation by recombinant Saccharomyces cerevisiae. Microb. Cell Fact. 6, 5. http://dx.doi.org/10.1186/1475-2859-6-5.

Kelbert, M., Romaní, A., Coelho, E., Pereira, F.B., Teixeira, J.A., Domingues, L., 2016. Simultaneous saccharification and fermentation of hydrothermal pretreated lignocellulosic biomass: evaluation of process performance under multiple stress conditions. Bioenergy Res., 1-13

Kelbert, M., Romaní, A., Coelho, E., Pereira, F.B., Teixeira, J.A., Domingues, L., 2015. Lignocellulosic bioethanol production with revalorization of low-cost agroindustrial by-products as nutritional supplements. Ind. Crops Prod. 64, $16-24$.

Kim, S.R., Ha, S.-J., Wei, N., Oh, E.J., Jin, Y.-S., 2012. Simultaneous co-fermentation of mixed sugars: a promising strategy for producing cellulosic ethanol. Trends Biotechnol. 30, 274-282.

Kim, S.R., Park, Y.-C., Jin, Y.-S., Seo, J.-H., 2013. Strain engineering of Saccharomyces cerevisiae for enhanced xylose metabolism. Biotechnol. Adv. 31, 851-861.

Ko, J.K., Um, Y., Woo, H.M., Kim, K.H., Lee, S.M., 2016. Ethanol production from lignocellulosic hydrolysates using engineered Saccharomyces cerevisiae harboring xylose isomerase-based pathway. Bioresour. Technol. 209, 290-296.

Koppram, R., Nielsen, F., Albers, E., Lambert, A., Wännström, S., Welin, L., Zacchi, G., Olsson, L., 2013. Simultaneous saccharification and co-fermentation for bioethanol production using corncobs at lab, PDU and demo scales. Biotechnol. Biofuels 6, 2.

Koppram, R., Tomás-Pejó, E., Xiros, C., Olsson, L., 2014. Lignocellulosic ethanol production at high-gravity: challenges and perspectives. Trends Biotechnol. 32, 46-53.

Lavoie, J.-M., Capek-Menard, E., Gauvin, H., Chornet, E., 2010. Production of pulp from Salix viminalis energy crops using the FIRSST process. Bioresour. Technol. 101, 4940-4946.

Lee, W., Kim, M., Ryu, W., Bisson, L., Seo, J., 2002. Kinetic studies on glucose and xylose transport in Saccharomyces cerevisiae. Appl. Microbiol. Biotechnol. 60, $186-191$.

Li, H., Wu, M., Xu, L., Hou, J., Guo, T., Bao, X., Shen, Y., 2015. Evaluation of industrial Saccharomyces cerevisiae strains as the chassis cell for second-generation bioethanol production. Microb. Biotechnol. 8, 266-274.

Li, Y.C., Mitsumasu, K., Gou, Z.X., Gou, M., Tang, Y.Q., Li, G.Y., Wu, X.L., Akamatsu, T., Taguchi, H., Kida, K., 2016. Xylose fermentation efficiency and inhibitor tolerance of the recombinant industrial Saccharomyces cerevisiae strain NAPX37. Appl. Microbiol. Biotechnol. 100, 1531-1542.

Matsushika, A., Inoue, H., Murakami, K., Takimura, O., Sawayama, S., 2009. Bioethanol production performance of five recombinant strains of laboratory 
and industrial xylose-fermenting Saccharomyces cerevisiae. Bioresour. Technol. 100, 2392-2398.

Moysés, D.N., Reis, V.C.B., de Almeida, J.R.M., de Moraes, L.M.P., Torres, F.A.G., 2016. Xylose fermentation by Saccharomyces cerevisiae: challenges and prospects. Int. J. Mol. Sci. 17, 1-18.

Parreiras, L.S., Breuer, R.J., Narasimhan, R.A., Higbee, A.J., La Reau, A., Tremaine, M., Qin, L., Willis, L.B., Bice, B.D., Bonfert, B.L., Pinhancos, R.C., Balloon, A.J., Uppugundla, N., Liu, T., Li, C., Tanjore, D., Ong, I.M., Li, H., Pohlmann, E.L., Serate, J., Withers, S.T., Simmons, B.A., Hodge, D.B., Westphall, M.S., Coon, J.J., Dale, B.E., Balan, V., Keating, D.H., Zhang, Y., Landick, R., Gasch, A.P., Sato, T.K., 2014. Engineering and two-stage evolution of a lignocellulosic hydrolysatetolerant Saccharomyces cerevisiae strain for anaerobic fermentation of xylose from AFEX pretreated corn stover. PLoS One 9.

Pereira, F., Azevedo, F. .De., Parachin, N.S., Gorwa-grauslund, M.F., Johansson, B., 2016. The Yeast Pathway Kit: a method for metabolic pathway assembly with automatically simulated executable documentation. ACS Synth. Biol.

Pereira, F.B., Guimarães, P.M.R., Teixeira, J.A., Domingues, L., 2010. Selection of Saccharomyces cerevisiae strains for efficient very high gravity bio-ethanol fermentation process. Biotechnol. Lett. 32, 1655-1661.

Pereira, F.B., Guimarães, P.M.R., Gomes, D.G., Mira, N.P., Teixeira, M.C., Sá-Correia, I., Domingues, L., 2011a. Identification of candidate genes for yeast engineering to improve bioethanol production in very gravity and lignocellulosic biomass industrial fermentations. Biotechnol. Biofuels 4, 57.

Pereira, F.B., Guimarães, P.M.R., Teixeira, J.A., Domingues, L., 2011b. Robust industrial Saccharomyces cerevisiae strains for very high gravity bio-ethanol fermentations. J. Biosci. Bioeng. 112, 130-136.

Pereira, F.B., Romaní, A., Ruiz, H.A., Teixeira, J.A., Domingues, L., 2014a. Industrial robust yeast isolates with great potential for fermentation of lignocellulosic biomass. Bioresour. Technol. 161, 192-199.

Pereira, F.B., Teixeira, M.C., Mira, N.P., Sá-Correia, I., Domingues, L., 2014b. Genomewide screening of Saccharomyces cerevisiae genes required to foster tolerance towards industrial wheat straw hydrolysates. J. Ind. Microbiol. Biotechnol. 41 (12), 1753-1761.

Pitkänen, J.P., Rintala, E., Aristidou, A., Ruohonen, L., Penttilä, M., 2005. Xylose chemostat isolates of Saccharomyces cerevisiae show altered metabolite and enzyme levels compared with xylose, glucose, and ethanol metabolism of the original strain. Appl. Microbiol. Biotechnol. 67, 827-837.
Purwadi, R., Brandberg, T., Taherzadeh, M.J., 2007. A possible industrial solution to ferment lignocellulosic hydrolyzate to ethanol: Continuous cultivation with flocculating yeast. Int. J. Mol. Sci. 8, 920-932.

Richard, P., Toivari, M.H., Penttilä, M., 1999. Evidence that the gene YLR070c of Saccharomyces cerevisiae encodes a xylitol dehydrogenase. FEBS Lett. 457, 135138.

Rivas, B., Domínguez, J.M., Domínguez, H., Parajó, J.C., 2002. Bioconversion of posthydrolysed autohydrolysis liquors: an alternative for xylitol production from corn cobs. Enzyme Microb. Technol. 31, 431-438.

Romaní, A., Pereira, F., Johansson, B., Domingues, L., 2015. Metabolic engineering of Saccharomyces cerevisiae ethanol strains PE-2 and CAT-1 for efficient lignocellulosic fermentation. Bioresour. Technol. 179, 150-158.

Romaní, A., Ruiz, H.A., Pereira, F.B., Teixeira, J.A., Domingues, L., 2014. Integrated approach for effective bioethanol production using whole slurry from autohydrolyzed Eucalyptus globulus wood at high-solid loadings. Fuel 135, 482-491.

Ruiz, H.A., Silva, D.P., Ruzene, D.S., Lima, L.F., Vicente, A.A., Teixeira, J.A., 2012. Bioethanol production from hydrothermal pretreated wheat straw by a flocculating Saccharomyces cerevisiae strain - effect of process conditions. Fuel 95, 528-536.

Runquist, D., Hahn-Hagerdal, B., Bettiga, M., 2010. Increased ethanol productivity in xylose-utilizing Saccharomyces cerevisiae via a randomly mutagenized xylose reductase. Appl. Environ. Microbiol. 76, 7796-7802.

Toivari, M.H., Aristidou, A., Ruohonen, L., Penttilä, M., 2001. Conversion of xylose to ethanol by recombinant Saccharomyces cerevisiae: importance of xylulokinase (XKS1) and oxygen availability. Metab. Eng. 3, 236-249.

Träaff, K., Cordero Otero, R.R., van Zyl, W.H., 2001. Deletion of the GRE3 aldose reductase gene and its influence on xylose metabolism in recombinant strains of Saccharomyces cerevisiae expressing the xylA and XKS1 genes. Appl. Environ. Microbiol. 67, 5668-5674.

Träff-Bjerre, K.L., Jeppsson, M., Hahn-Hägerdal, B., Gorwa-Grauslund, M.F., 2004. Endogenous NADPH-dependent aldose reductase activity influences product formation during xylose consumption in recombinant Saccharomyces cerevisiae. Yeast 21, 141-150.

Zaldivar, J., Nielsen, J., Olsson, L., 2001. Fuel ethanol production from lignocellulose: a challenge for metabolic engineering and process integration. Appl. Microbiol. Biotechnol. 56, 17-34. 